\title{
Augmented Reality Affects Students' Attitude and Conceptual Understanding in Learning 3D Geometry
}

\author{
Risma Nurul Auliya ${ }^{1 *}$, Munasiah ${ }^{2}$ \\ 1,2Informatics Department, Universitas Indraprasta PGRI, Jakarta, Indonesia \\ e-mail: rismauliya@gmail.com,13munasiah@gmail.com
}

\begin{abstract}
The study investigates the impact of using AR in learning $3 D$ geometry on students' attitudes and conceptual understanding. The research was carried out using a quasi-experimental design, in particular by using a conceptual understanding test and attitude towards geometry questionnaire, in a public secondary school in Rangkasbitung, Banten, Indonesia. Two groups of students were used for data collection; the experimental (31 students) and the control groups (30 students). The data analyzed by independent sample t-test, using a significant level of 0.05. The results of this study were: (1) students' conceptual understanding in mathematics in AR group was better than the control group, (2) students' conceptual understanding in mathematics for both groups was in the medium category, and (3) students' attitude towards geometry in AR group was better than the control group. Therefore, the appropriate method that is used in learning geometry can affect students' conceptual understanding and attitude towards geometry. Additionally, the learning environment also needs to be teachers' attention, because it can affect students' involvement in the learning process.
\end{abstract}

Keywords: Conceptual Understanding in Mathematics; Attitude Towards Geometry; Learning 3D Geometry; Augmented Reality

\section{Introduction}

Geometry is an important and essential branch of mathematics, which studies shapes and space, in two-dimensional (2D) and three-dimensional (3D), along with their characteristics (Aktaş \& Aktaş, 2012; Paulina, 2007, in Fabiyi, 2017; Serin, 2018). Understanding of geometry concepts is essential and it should be developed effectively in learning mathematics because it allows students to analyze and interpret the world they live in as well as equip them with tools they can apply in other areas of mathematics (Özerem, 2012). Geometry learning involves the ability to visualize because it requires the students to visually perceive the objects and their properties by comparing them with their previous experiences involving similar objects (Idris, 2005). Learning and solving geometry problems should be challenging, but it can be fun for someone who has a good conceptual understanding of geometry (Gloria, 2015). Students with good conceptual understanding should be able to apply certain concepts to solve the problems (Greeno, Riley, Gelman, 1984). In addition, to teach geometry effectively, it is important to ensure that students understand the concepts they learn and the procedures that are involved in a particular process rather than the students solely learning rules (Jones, 2002).

However, the results of numerous studies showed that some students face difficulties mastering geometry concepts, besides they have to memorize and follow sets of rules to solve problems (Dobbins, Gagnon, \& Ulrich, 2013; Melo \& Martins, 2015). One of the reasons of this was the limited teaching of geometry, which represents three-dimensional solids, teachers usually provide an explanation of the content by drawings on the whiteboard, pictures in the book, and verbal explanations, and this method is known as traditional teaching (Nunesl, Duart, \& Donato, 2018; İbili, Çat, Resnyansky, Şahin, \& Billinghurst, 2019). Traditional learning methods made students learn passively ( $\mathrm{Li}, 2016)$ since they have too much time listening to facts and watching teachers introduced geometry concepts and theorems on the board and in front of the classroom without any students' contribution in formulating the knowledge

\footnotetext{
* Corresponding author.

Received 4 May 2019; Accepted 22 June 2020; Available online 20 June 2020

(C) 2020 JPI. All Rights Reserved
} 
(Abdelfatah, 2011). Whereas, geometry needs a strong pedagogical approach besides deep knowledge to be able to provide an enjoyable atmosphere for students (Serin, 2018). Serin (2018) also added that the role of a teacher is to guide students to have better and comfortable thinking rather than to force students to think in his/her limits. Therefore, it is necessary to find a learning source that can be used to present the concepts understandably, so that it can help students have a better understanding of geometry concepts and encourage active involvement in their learning process.

The development of information and communication technologies in the education area provides a change in the traditional learning environment. Technology has an important role in effective strategies in schools (Mundy, Hernandez, \& Green, 2019). Pantely \& Panaoura (2020) identified that the use of technology in geometry is proposed to facilitate the examination or investigation of concepts. Some researchers introduce new learning methods that can be used to enhance learning and teaching experiences, and Almenara, et al. (2019) assumed that one of the emerging technologies that are gaining greater influence on teaching is Augmented Reality (AR). Simulation software, such as AR, has frequently been touted as a disruptive innovation in education, and it can potentially support learning and teaching (Bujak et al, 2013; Liao, Yu, \& Wu, 2015; Akçayır \& Akçayır, 2016; Da Silva, Teixeira, Cavalcante, \& Teichrieb, 2019).

In geometry, AR serves as a tool for creating virtual manipulatives on children's understanding of geometric shapes, where it provides dynamic virtual models which can be used as instructional tools that students can manipulate by sliding, flipping, turning, and rotating geometry objects (Gecu-Parmaksiz \& Delialioglu, 2019). AR can help students to understand abstract and complex concepts by fostering their creativity and imagination to subjects (Bistaman, Idrus, \& Rashid, 2018). AR builds bridges between abstract and concrete representations by utilizing the physicality of the real environment surrounding the learner (İbili et al., 2019). AR technology also has the potential ability to visually convey abstract concepts and present virtual objects such as 3D models by combining them with real-world images (Pérez-López \& Contero, 2013; Westerfield, Mitrovic, \& Billinghurst, 2015).

Furthermore, some other studies showed that AR has the potential to engage, encourage, and motivate learners to explore material from a variety of differing perspectives (Estapa \& Nadolny, 2015; Bistaman et al., 2018). Using AR requires student involvement in the learning process, visualizing 3D virtual objects into the real ones, presenting the viewing of phenomena that unperceivable in the real world in scale, as well as through different perspectives and angles (Herpich, Guarese, \& Tarouco, 2017). In addition, Herpich et al. (2017) argued that the AR is easy to be used, requires little time to be learned, and encourages the students to explore geometry properly.

Hence, this matter deserves serious attention from related parties since both variables (conceptual understanding and attitude) are the objectives explicitly describes in the school curriculum of which to be achieved at the end of the lessons. In the current study, the impacts of using AR in learning geometry towards students' attitudes and conceptual understanding were investigated.

\section{Method}

\subsection{Research Design}

The research method of this study was a quasi-experimental design. Because of legislative limitations, the researchers could select only one school that was as typical as possible among a few numbers of available schools to have an as representative as a possible sample for the quasi-experimental design.

\subsection{Participants}

The study was conducted during the 2018-2019 academic year at a public secondary school in Rangkasbitung, Banten, Indonesia. A total of 61 students in grade nine participated in the study, and they are divided into two groups, namely the experimental (31 students) and the control group (30 students). The students in the experimental group learned a 3D geometry topic using AR application. On the other hand, the control group learned the same topic using 
textbooks (traditional methods). Before the sequenced lessons, all participants were informed that their participation was voluntary, and all responses would be kept completely confidential and would not affect their mathematics scores in school.

\subsection{Instruments}

Data obtained from the results of the conceptual understanding in mathematics test and the questionnaire of attitude towards geometry carried out by students. Five essay questions were used to measure students' conceptual understanding in mathematics, before and after the treatment. A higher score means a higher level of skills in conceptual understanding. Precisely, a pretest-posttest experimental and control group research design was employed for the study. A pretest was administered to determine the equivalence of both groups. At the end of the treatment period, a posttest was administered to evaluate the effectiveness of the treatment on students' conceptual understanding in mathematics. The questions for both tests were the same. All of the participants were invited to take the pretest before the lessons as well as the posttest after the completion of the lessons.

Students are also asked to fill out the attitude towards geometry survey, to examine students' attitudes towards geometry learning. This survey is an instrument adapted from surveys developed by Dede (2012) and Sunzuma, Masocha, \& Zezekwa (2013), which comprised of four indicators, namely: enjoyment, anxiety, efficacy, and usefulness of geometry. This study implemented the 16 items modified version, with overall reliability of 0.753 . The items consist of positive and negative statements. The statements were anchored using a 4-point Likert-type rating ( $1=$ strongly disagree, $2=$ disagree, $3=$ agree, $4=$ strongly agree). No neutral point was included to get the respondents to voice an opinion. Negatively worded items were later reverse coded. A high score shows a high positive attitude towards geometry. The selected items from the survey are as shown in Table 1.

Table 1. Selected Items from Attitude Towards Geometry Survey

\begin{tabular}{cl}
\hline Aspect & \\
\hline Anxiety & I am afraid of geometry subjects* \\
Enjoyment & Geometry is hard for me to learn* \\
& Geometry subjects are boring for me* \\
& Geometry interests me \\
& Geometry is an enjoyable subject for me \\
& I like geometry subjects \\
& I would not like to learn geometry subjects* \\
& I learn geometry subjects willingly \\
& I would like to dedicate most of my study time to the geometry \\
& I would like further information about the geometry \\
& I know I can do well in geometry \\
& Only brilliant students can understand geometry* \\
& Geometry has been my worst area in Mathematics* \\
Efficacy & Geometry subjects don't help the intellect development* \\
& It would be better if geometry subjects are not taught in schools \\
& I can apply geometry subjects in daily life
\end{tabular}

*negative item

\subsection{Data Analysis}

Both sets of tests were run on an SPSS package, using significance level 0.05. The data analyzed by independent sample t-test, to examine that there is a significant difference of conceptual understanding in mathematics and attitude towards geometry between control and experimental groups. The data that collected from the results of questionnaire and test, proceed through these stages: (1) give scoring for students' answer refer to answer key and guidelines scoring; (2) statistics assumption trial, namely normality and homogeneity; and (3) independent sample t-test analysis. 


\subsection{Learning Materials}

The current study used learning materials developed by Auliya \& Munasiah (2019), regarding learning geometry $3 \mathrm{D}$ using $\mathrm{AR}$ technology based on marker. The geometrical objects in course materials were designed by Sketchup, and Augment for Sketchup plugin turns the uploading models into QR code (as a tracker). Then, the students could use their mobile phone to view 3D objects which were coming out from the pages, and the virtual objects can be seen from different angles in a 3-dimensional way. Previously, students have to install an 'Augment' application that can be download for free on smartphones. The example of learning materials could be seen in Figures 1 and 2.

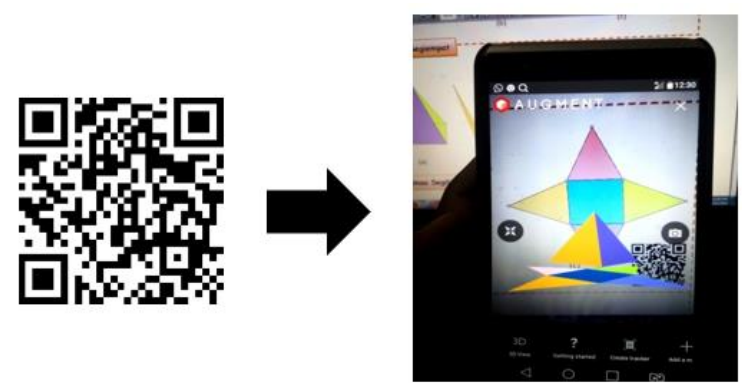

Figure 1. The marker (QR code) is scanned by using an Augment application.

B. Face Diagonal of Cube

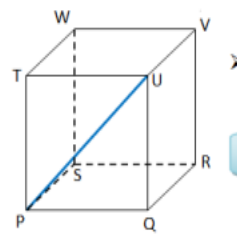

If $\mathrm{P}$ and $\mathrm{U}$ vertex were connected, then it will create PU line.

PU line is Face diagonal of cube PQRS.TUVW

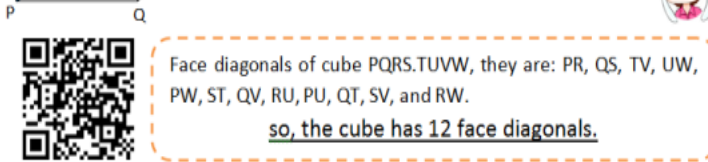

C. Pyramid Net

Triangular Pyramid

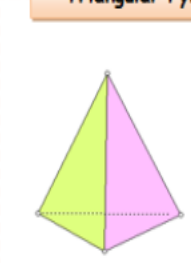

(a)

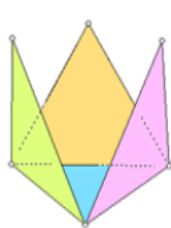

(b)

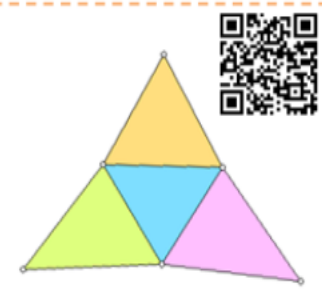

(c)
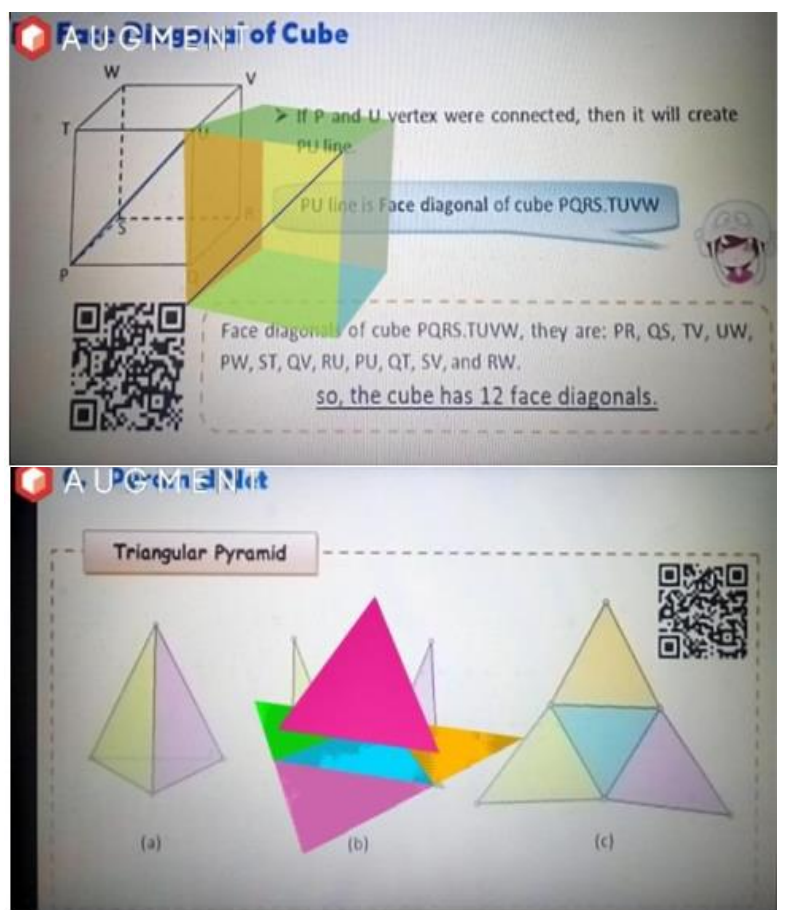

Figure 2. Learning materials to explain geometry objects.

\section{Results and Discussion}

\subsection{Results}

\section{Descriptive Statistics}

According to results obtained, the mean, standard deviation, minimum and maximum score of conceptual understanding in mathematics are as table 2. It is recorded in Table 2, that the mean of pretest score in both groups is not much different, there are 10.58 for the AR group and 21.68 for the control group. Then, the mean of the posttest score is 18.65 (AR group) and 17.00 (control group), while the mean of students' posttest scores in the AR group is higher than students in the control group, (18.65 for AR group and 17.00 for the control group). Besides, the AR group has a higher standard deviation than the control group, so it 
means that students' conceptual understanding in the mathematics of the AR group is more variated than the control group. The table below also showed that the score minimum for the AR group's pretest is lower than the control group, around 2 points, and the score minimum for the posttest for both groups is the same. While, score maximum of pretest and posttest for the AR group is higher than the control group, around 2 points for pretest and 3 points for posttest. It can be said that learning geometry with AR affects the students' conceptual understanding of mathematics.

Table 2 also shows that students in the AR group have higher means of attitude towards geometry than students in the control group, there are 21.26 for the AR group, and 19.03 for the control group. Furthermore, the AR group has a higher standard deviation than the control group, so it means that students' attitude geometry of the AR group is more variated than the control group. Meanwhile, the score minimum and maximum for both groups are the same.

Table 2. Descriptive Statistics of Conceptual Understanding in Mathematics

\begin{tabular}{lcccccc}
\hline & \multicolumn{2}{c}{ Pretest } & \multicolumn{2}{c}{ Posttest } & \multicolumn{2}{c}{ Attitude } \\
\cline { 2 - 7 } & AR & Control & AR & Control & AR & Control \\
\hline $\mathrm{N}$ & 31 & 30 & 31 & 30 & 31 & 30 \\
$\mathrm{X}_{\min }$ & 4 & 6 & 11 & 11 & 12 & 12 \\
$\mathrm{X}_{\max }$ & 18 & 16 & 24 & 21 & 27 & 27 \\
$\overline{\boldsymbol{x}}$ & 10.58 & 11.13 & 18.65 & 17.00 & 21.26 & 19.03 \\
$\mathrm{SD}$ & 3.34 & 2.72 & 3.25 & 2.60 & 3.34 & 2.72 \\
\hline \multicolumn{7}{r}{} \\
\hline
\end{tabular}

Independent sample t-test analysis is conducted on the data to determine differences between experimental and control groups in terms of students' conceptual understanding in mathematics and attitudes towards geometry scores, with the following hypothesis:

$\mathrm{H}_{0_{1}}$ : There is no significant difference between experimental and control groups in terms of students' conceptual understanding of mathematics scores.

$\mathrm{H}_{\mathrm{O}_{2}}$ : There is no significant difference between experimental and control groups in terms of students' attitudes towards geometry scores.

Several tests were performed to fulfill assumptions made before the independent sample t-test, namely: normality and homogeneity. Shapiro-Wilk test was used for testing the normality of the data, while Levene's test was used for testing the homogeneity. The results of both tests in terms of students' conceptual understanding in mathematics and attitudes towards geometry scores showed that the data fulfilled normality assumed and the variance is homogeneous.

$\mathrm{H}_{0_{1}}$ mention above is to test the hypothesis regarding the students' conceptual understanding in mathematics. In this study, according to the results in Table 3 , we found that there is no statistically significant difference of pretest means between two groups for students' conceptual understanding ability in mathematics ( $p>0.05$, the null hypothesis is accepted). It can be said that both groups have the same initial abilities. On the contrary, the posttest and $\mathrm{n}$-gain scores have $\mathrm{p}<0.05$, then the null hypothesis is rejected. In a word, there is a significant difference between experimental and control groups in terms of students' conceptual understanding of mathematics scores. Furthermore, based on the results shown in Table 3, the mean of $n$-gain scores for the AR group is higher than the control group (0.58 for the AR group and 0.43 for the control group). Therefore, from the results in Table 3 and 4 , we can conclude that students in AR group have better conceptual understanding in mathematics than students in the control group, and the classification of $n$-gain scores for both groups are in the medium category. 
Table 3. The Results of Independent Sample T-test

\begin{tabular}{cccc}
\hline & \multicolumn{2}{c}{ t-test for Equality of Means } & Criteria \\
\cline { 2 - 3 } & $\mathbf{p}$ & $\mathbf{d f}$ & \\
\hline Pretest & 0.483 & 59 & $\mathrm{H}_{0}$ is accepted \\
Posttest & 0.033 & 59 & $\mathrm{H}_{0}$ is rejected \\
N-gain & 0.000 & 59 & $\mathrm{H}_{0}$ is rejected \\
Attitude & 0.017 & 59 & $\mathrm{H}_{0}$ is rejected \\
\hline
\end{tabular}

Table 4. N-gain Classification

\begin{tabular}{ccc}
\hline Group & Mean of N-gain & Classification \\
\hline AR & 0.58 & Medium \\
Control & 0.43 & Medium \\
\hline
\end{tabular}

$\mathrm{H}_{0_{2}}$ mention above is to test the hypothesis regarding the students' attitude towards geometry. Based on the results in Table 3, we can be seen that there is a significant difference between experimental and control groups in terms of students' attitudes towards geometry scores $(p=0.017<0.05)$. In other words, the group using an AR lesson has a more positive attitude towards geometry than the control group, with the AR and control groups' mean scores are 21.26 and 19.03, respectively (see Table 2).

\section{Mean Scores for Attitude towards Geometry}

The respondents have exhibited their agreement and disagreement towards the items in the component. As can be seen in Table 5, the mean scores for attitude towards geometry students are presented. Students in two groups are found to show a positive attitude in every component (anxiety, enjoyment, efficacy, and usefulness of geometry). However, the control group has lower scores than the AR group for all items, except e6. Most students assume that geometry is a subject that has to be taught in school because it is useful in daily life. In addition, they consider geometry as an enjoyable subject, and they are confident that they can do well in geometry, even though some of them have difficulties and worries to learn geometry.

Table 5. Mean Scores for Attitude towards Geometry

\begin{tabular}{|c|c|c|}
\hline \multirow{2}{*}{ Statement } & \multicolumn{2}{|c|}{ Mean } \\
\hline & AR & Control \\
\hline I am afraid of geometry subjects* & 2.87 & 2.70 \\
\hline Geometry is hard for me to learn* & 2.65 & 2.33 \\
\hline Geometry subjects are boring for $m e^{*}$ & 3.00 & 2.70 \\
\hline Geometry interests me & 3.16 & 3.03 \\
\hline Geometry is an enjoyable subject for me & 3.13 & 2.90 \\
\hline I like geometry subjects & 3.03 & 2.97 \\
\hline I would not like to learn geometry subjects* & 3.13 & 2.93 \\
\hline I learn geometry subjects willingly & 3.13 & 3.23 \\
\hline I would like to dedicate most of my study time to the geometry & 2.87 & 2.70 \\
\hline I would like further information about the geometry & 3.13 & 3.07 \\
\hline I know I can do well in geometry & 3.26 & 2.97 \\
\hline Only brilliant students can understand geometry* & 3.42 & 3.00 \\
\hline Geometry has been my worst area in Mathematics* & 3.00 & 2.67 \\
\hline Geometry subjects don't help the intellect development* & 3.16 & 2.83 \\
\hline It would be better if geometry subjects are not taught in schools* & 3.45 & 3.17 \\
\hline I can apply geometry subjects in daily life & 3.13 & 2.77 \\
\hline
\end{tabular}

\subsection{Discussion}

The independent sample t-test results indicate that using AR in learning geometry was efficient in terms of contributing to students' conceptual understanding in mathematics. The students in the AR group can apply the geometry concepts to solve mathematics problems. In line with the results of the previous study was conducted by Mundy et al. (2019), which 
stated that $A R$ adds information to a real environment such as the classroom to improve students' engagement as well as content understanding. Bujak et al. (2013) also identified that AR allows students to experience interactive 3D simulations, which leads to deeper insights about phenomena that may be difficult to explore. The group of students cooperates in a learning activity with AR application in the class using the mobile phone as shown in Figure 3.
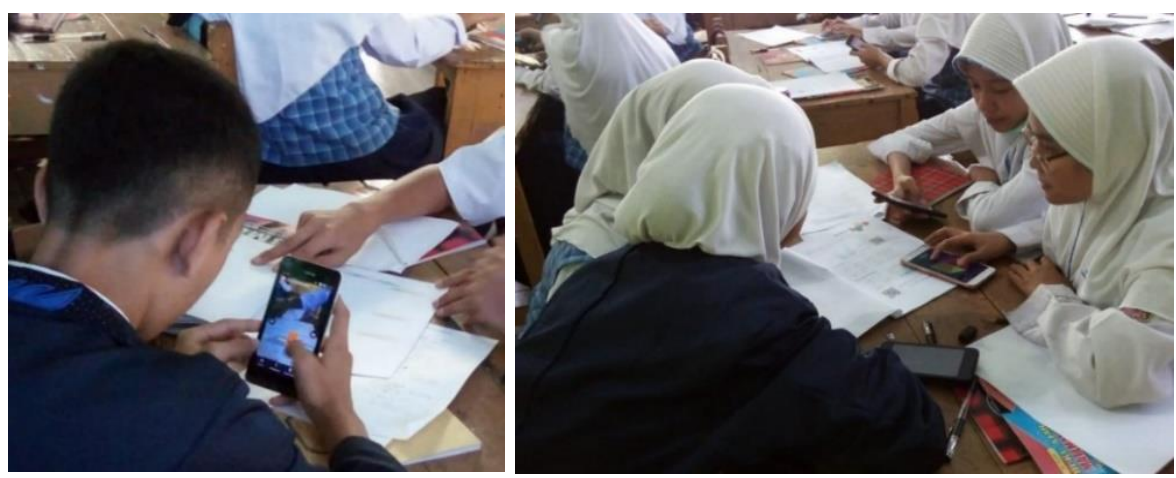

Figure 3. Students' activities during learning 3D geometry using the AR application.

Students were allowed to explore geometry objects on his/her own. AR technology allows students to interact with the educational content, they can move around the objects to change perspective, and move closer/ farther to change scale (Bujak et al., 2013), which lead to a better understanding of concepts (Kiryakova, Angelova, \& Yordanova, 2018), and make the students' academic performance better (Kamal \& Junaini, 2019). The AR application provides a dynamic virtual model that can be used as a learning material that students can manipulate by sliding, flipping, turning, and rotating the geometrical objects (Gecu-Parmaksiz \& Delialioglu, 2019). In other words, using AR in learning geometry provides opportunities for students to interact with the 3D information, object, and events in a natural way (Kesim \& Ozarslan, 2012), so they have distinct roles to play to develop an in-depth understanding about a topic (Wu et al., 2013). Corresponding to the basic goal of an AR system, which is to improve the user's perceptions and interaction with the real world through supplementing the real world with 3D virtual objects that appear to coexist in the same space as the real world (Lilla \& Ján, 2018).

Furthermore, this study also found that AR lessons have influences on students' attitudes towards geometry. Students who learn geometry with AR have more positive attitudes than students who learn geometry without AR. The majority of respondents show a high interest and excitement in understanding AR content. Although, students showed a very low confidence level in the beginning phase because they were still new to the whole AR concept. But finally, they found out the learning process was fun, interactive, and motivated them to learn more about geometry. AR assisted them to better grasp the subject content and made them more enthusiastic about the learning process in the classroom. The results are in line with the findings of the study conducted by Akçayır \& Akçayır (2016) and Liu et al. (2018), which indicated that AR can help students to understand, enhance learning motivation, positive attitude, and satisfaction.

Chiang, Yang \& Hwang (2014) reported that AR technology can be an alternative learning tool to increases students' learning motivation because it forces them to search relevant information regarding their learning content on their own. In the AR learning process, students are given opportunities to explore their mathematics concepts rather than being fed with math facts (Abdullah et al., 2014). Adopting any technology tool in education is not necessarily bound to its newness and innovation alone, but its effectiveness in engaging and motivating students and creating an enjoyable learning environment (Mundy et al., 2019). Being aware of the students' attitudes towards geometry will be useful for teachers so that teachers would identify the students who have negative attitudes towards geometry and would take required precautions (Aktaş \& Aktaş, 2012). 
Learning geometry based on AR was also described as easy in use on the part of the teacher, which enabled him to engage intensively the learners in the learning situation. AR could be used to create interactive learning materials that could be contributing to extend the class into a virtual space where students could have more chances to improve their geometry ability (Auliya \& Munasiah, 2019). In addition, learning geometry with AR brings the advantage that the work of teachers can be made more effective, because they can create an enjoyable, interesting, and interactive learning atmosphere (Lilla \& Ján, 2018; Yingprayoon, 2015). By using geometrical images as a tracker to create AR objects, the students paid more attention to geometry class and actively participate in the learning process (Yingprayoon, 2015; AlAsheeri, 2017; Kiryakova et al., 2018; Lilla \& Ján, 2018).

\section{Conclusion}

The conclusions that could be obtained from this study were using AR in learning 3D geometry was effective in improving students' conceptual understanding in mathematics. As could be seen from the result of data analysis which showed that students who learn geometry with AR technology had a better understanding of mathematical concepts than students who learn geometry with traditional learning (using textbook). Furthermore, the enhancement of conceptual understanding in mathematics for both groups (AR and controlled group) was in the medium category. Additionally, AR also has an impact on students towards geometry. Students who learn geometry within AR groups have a more positive attitude towards geometry rather than students who learn without AR.

\section{Acknowledgment}

This research was supported by the Ministry of University and Research under the PDP program, with grant no. 032/K3/PNT/2018, 6 March 2018, and 0313/SKP.LT/LPPM/UNINDRA/III/2018, 12 March 2018. We would also like to show our gratitude to LLDIKTI area III Jakarta and LPPM Universitas Indraprasta PGRI for the expertise and insight that greatly assisted the research.

\section{References}

Abdelfatah, H. (2011). A story-based dynamic geometry approach to improve attitudes toward geometry and geometric proof. ZDM Mathematics Education, 43, 441-450.

Abdullah, A. H., Ibrahim, N. H., Surif, J., \& Zakaria, E. (2014). The effects of van hiele's phasebased learning on students ' geometric achievement and attitude towards geometry. International Conference on Teaching and Learning in Computing and Engineering, 317324. https://doi.org/10.1109/LaTiCE.2014.67

Akçayır, M., \& Akçayır, G. (2016). Advantages and challenges associated with augmented reality for education: a systematic review of the literature. Educational Research Review, 20, 1-11. https://doi.org/10.1016/j.edurev.2016.11.002

Aktaş, M. C., \& Aktaş, D. Y. (2012). Investigating high school students' attitudes towards geometry according to different variables: sample of Ordu City. Dicle Üniversitesi Ziya Gökalp Eğitim Fakültesi Dergisi, 18, 156-167.

Al-Asheeri, H. A. Y. (2017). Effectiveness of using augmented reality strategy in enhancing learning english for cycle one students in the elementary stage in the Kingdom of Bahrain. US-China Foreign Language, 15(7), 409-419. https://doi.org/10.17265/15398080/2017.07.001

Almenara, J. C., Osuna, J. B., Cejudo, C. L., \& Martínez, M. D. M. F. (2019). Educational uses of augmented reality (AR): experiences in educational science. Sustainability, 11, 1-18.

Auliya, R. N. \& Munasiah. (2019). Mathematics learning instrument using augmented reality for learning 3D geometry. Journal of Physics: Conference Series, 1-5. https://doi.org/10.1088/1742-6596/1318/1/012069

Bistaman, I. N. M., Idrus, S. Z. S., \& Rashid, S. A. (2018). The use of augmented reality technology for primary school education in Perlis, Malaysia. Journal of Physics: Conference Series, 1019, 1-9. https://doi.org/10.1088/1742-6596/1019/1/012064 
Bujak, K. R., Radu, I., Catrambone, R., Maclntyre, B., Zheng, R., \& Golubski, G. (2013). A psychological perspective on augmented reality in the mathematics classroom. Computer \& Education, 68, 536-544.

Chiang, T. H. C., Yang, S. J. H., \& Hwang, G. J. (2014). An augmented reality-based mobile learning system to improve students' learning achievements and motivations in natural science inquiry activities. Educational Technology \& Society, 17(4), 352-365.

Da Silva, M. M. O., Teixeira, J. M. X. N., Cavalcante, P. S., \& Teichrieb, V. (2019). Perspectives on how to evaluate augmented reality technology tools for education: a systematic review. Journal of the Brazilian Computer Society, 25(3), 1-18. https://doi.org/10.1186/s13173-019-0084-8

Dede, Y. (2012). Students' attitudes towards geometry: a cross-sectional study. Jornal Internacional de Estudos Em Educação Matemática, 5(1), 85-113. https://doi.org/10.17921/2176-5634.2012v5n1p\%p

Dobbins, A., Gagnon, J. C., Ulrich, T. (2013). Teaching geometry to students with math difficulties using graduated and peer-mediated instruction in a response-to-intervention model. Preventing School Failure, 58(1), 17-25.

Estapa, A. \& Nadolny, L. (2015). The effect of an augmented reality enhanced mathematics lesson on student achievement and motivation. Journal of STEM Education: Innovations and Research, 16(3), 40-48.

Fabiyi, T. R. (2017). Geometry concepts in mathematics perceived difficult to learn by senior secondary school students in Ekiti State, Nigeria. IOSR Journal of Research \& Method in Education (IOSRJRME), 7(1), 83-90. https://doi.org/10.9790/7388-0701018390

Gecu-Parmaksiz, Z., \& Delialioglu, O. (2019). Augmented reality-based virtual manipulatives versus physical manipulatives for teaching geometric shapes to preschool children. British Journal of Educational Technology, 1-15. https://doi.org/10.1111/bjet.12740

Gloria, C. C. 2015. Mathematical competence and performance in geometry of high school students. International Journal of Science and Technology, 5(2), 53-69.

Greeno, J. G., Riley, M. S., \& Gelman, R. (1984). Conceptual competence and children's counting. Cognitive Psychology, 16, 94-143.

Herpich, F., Guarese, R. L. M., \& Tarouco, L. M. R. (2017). A comparative analysis of augmented reality frameworks aimed at the development of educational applications. Creative Education, 8, 1433-1451. https://doi.org/10.4236/ce.2017.89101

İbili, E., Çat, M., Resnyansky, D., Şahin, S., \& Billinghurst, M. (2019). An assessment of geometry teaching supported with augmented reality teaching materials to enhance students' 3D geometry thinking skills. International Journal of Mathematical Education in Science and Technology, 1-23. https://doi.org/10.1080/0020739X.2019.1583382

Idris, N. 2005. Teaching and Learning of Mathematics. Kuala Lumpur: Utusan Publications \& Distributors Sdn Bhd.

Jones, K. (2002). Issues in the teaching and learning of geometry. In: Linda Haggarty (Ed), Aspects of Teaching Secondary Mathematics: perspectives on practice, chapter 8, 121139. London: RoutledgeFalmer.

Kamal, A. A., \& Junaini, S. N. (2019). The effects of design-based learning in teaching augmented reality for pre-university students in the ict competency course. International Journal of Scientific and Technology Research, 8(12), 2726-2730.

Kesim, M., \& Ozarslan, Y. (2012). Augmented reality in education: current technologies and the potential for education. Procedia - Social and Behavioral Sciences, 47, 297-302. https://doi.org/10.1016/j.sbspro.2012.06.654

Kiryakova, G., Angelova, N., \& Yordanova, L. (2018). The potential of augmented reality to transform education into smart education. TEM Journal, 7(3), 556-565. https://doi.org/10.18421/TEM73-11

$\mathrm{Li}, \mathrm{Y}$. W. (2016). Transforming conventional teaching classroom to learner-centred teaching classroom using multimedia-mediated learning module. International Journal of Information and Education Technology, 6(2), 105-112. https://doi.org/10.7763/ijiet.2016.v6.667 
Liao, Y. T., Yu, C. H., \& Wu, C. C. (2015). Learning geometry with augmented reality to enhance spatial ability. International Conference on Learning and Teaching in Computing and Engineering, LaTiCE 2015, 221-222. https://doi.org/10.1109/LaTiCE.2015.40

Lilla, K., \& Ján, G. (2018). Augmented reality in mathematics education for pre-service teachers in primary level. Proceedings of 17th Conference on Applied Mathematics (APLIMAT), 597-605.

Liu, E., Li, Y., Cai, S., \& Li, X. (2019). The effect of augmented reality in solid geometry class on students/ learning performance and attitudes. International Conference on Remote Engineering and Virtual Instrumentation, 549-558.

Melo, H. S. \& Martins, M. C. (2015) Behaviors and attitudes in the teaching and learning of geometry. European Scientific Journal, 98-104.

Mundy, M. A., Hernandez, J., \& Green, M. (2019). Perceptions of the effects of augmented reality in the classroom. Journal of Instructional Pedagogies, 22, 1-15. Retrieved from http://www.aabri.com/copyright.Augmented

Nunesl, S. da C., Duart, M. A. no, \& Donato, F. M. R. (2018). Teaching and learning process of spatial geometry using augmented reality. International Journal of Education and Research, 6(6), 337-346.

Özerem, A. (2012). Misconceptions in geometry and suggested solutions for seventh grade students. Procedia - Social and Behavioral Sciences, 55, 720-729. https://doi.org/10.1016/j.sbspro.2012.09.557

Pantely, P. \& Panaoura, A. (2020). The effectiveness of using mobile learning methods in geometry for students with different initial mathematics performance. Social Education Research, 1(1), 1-10.

Pérez-López, D. \& Contero, M. (2013). Delivering educational multimedia contents through an augmented reality application: a case study on its impact on knowledge acquisition and retention. The Turkish Online Journal of Educational Technology, 12(4), 19-28.

Serin, H. (2018). Perspectives on the teaching of geometry: teaching and learning methods. Journal of Education and Training, 5(1), 131-137.

Sunzuma, G., Masocha, M., \& Zezekwa, N. (2013). Secondary school students' attitudes towards their learning of geometry: a survey of bindura urban secondary schools. Greener Journal of Educational Research, 3(8), 402-410. https://doi.org/10.15580/gjer.2013.8.051513614

Westerfield, G., Mitrovic, A., \& Billinghurst, M. (2015). Intelligent Augmented Reality Training for Motherboard Assembly. Int J Artif Intell Educ, 25, 157-172.

Wu, H. K., Lee, S. W. Y., Chang, H. Y., \& Liang, J. C. (2013). Current status, opportunities and challenges of augmented reality in education. Computers \& Education, 62, 41-49. https://doi.org/10.1016/j.compedu.2012.10.024

Yingprayoon, J. (2015). Teaching mathematics using augmented reality. Proceeding of the 20th Asian Technology Conference in Mathematics, 384-391. 